\title{
COVID19: Growing Rage and New Appearing Challenges for Upcoming Dentistry
}

\author{
Mayank Singhal, Manoj Goyal and Pratibha Kaushik* \\ Santosh Dental College, Santosh Deemed to be University, India \\ *Corresponding Author: Pratibha Kaushik, Santosh Dental College, Santosh \\ Deemed to be University, India.
}

Received: September 07, 2020

Published: October 07, 2020

(C) All rights are reserved by Pratibha

Kaushik, et al.

\begin{abstract}
The corona virus (COVID-19) has summoned health care professionals and it has evoked different types of reactions all around the world. Although routine general dental procedures have been suspended in countries influenced by COVID-19 disease, the requirement for assembled high priority care given by health care professionals with personal protective equipment takes precedence. With all the ignition of details available online, it becomes hard to bracket authentic guidance, this article is primarily based on the facts associated with precautions and preventions measures to be taken by dental health care professionals.
\end{abstract}

Keywords: COVID-19; Dentistry; SARS-CoV-2

\section{Introduction}

COVID-19 disease is primarily caused by SARS-CoV-2, which generally spreads by respiratory droplets whenever an infected individual talks, sneezes or coughs. Airborne Transmission from one person to another from distance is yet not reported [1]. However, COVID-19 is disease new to us and research is ongoing regarding its severity and pathogenesis. It is believed that the virus survives in aerosols for hours and continues to survive for days. It has also been observed and reported that the patients may continue to transmit the virus in the asymptomatic and in their pre-symptomatic period as well [2].

The execution of basic dentistry necessitates the regime usage of rotary equipments. Instrumentation for functioning tends to creates large volume of aerosols and particle droplet such as saliva, blood, water and microorganisms. This splash ranges a very brief distance and settles on the floor, operatory surfaces and operator [3]. Standard three-ply masks provide promising protection against the splatter of aerosols limited to mucous membranes of the mouth and nose, but they lack to provide absolute protection against aspiration of airborne infections.
Due to insufficiency of availability of data for assessment of risk factors associated with SARS-CoV-2, the Occupational Safety and Health Administration has issued Guidelines on arranging dental offices and hospitals. According to the studies dental surgeons are prone to very high exposure and categorised in high risk category due to peculiarity of profession that involves infectious exposure in abundance [4].

Execution of dentistry in paucity of specific safeguard against airborne transmission, the risk of transference of SARS-CoV-2 associated with generation of aerosols during dental procedures cannot be eliminated. Patient care correlated with Airborne Precautions is unfeasible as most of the dental offices are not equipped and designed accordingly.

For example, utmost dental offices do not have isolation rooms for airborne precaution and routine use of N95 mask is not generally practised [5].

\section{Recommendations for dental surgeons}

- $\quad$ All the non-urgent dental visits, elective procedures should be deferred. 
- Only the emergency services should remain open.

- In case of feeling sick, should stay at home.

- Telephonic screening of signs or symptoms of the patient should be done prior so as to rule out any respiratory distress like fever, cough and shortness of breath. If the patient reports signs or symptoms of a respiratory disease, avoid attending. If in case patient gives positive history regarding symptoms of respiratory distress avoid attending the patient [6].

- $\quad$ Try consulting the patients before giving appointments for any Emergency Dental Treatment. If dental treatment has to be deferred or delayed, patient should be provided with descriptive home care instructions with suitable medications.

Amenities of urgent care to patients with COVID-19

If a patient is suspected or reported as COVID-19 positive:

- Deferral of all dental treatments should be done.

- $\quad$ N-95 face masks and face shields should be provided to the patients.

- If patients give history of acute illness, he or she should be advised to stay home and rest and should be referred to medical facility.

- In cases where medical intervention is unavoidable and needs immediate attention, cases should be done in the hospitals or setups with proper preventive equipments [7].

Disease domination ventures

As the sheer component of disease control endeavour operator is advised to keep wearing the face mask and shields.

- $\quad$ Usage of N-95 mask gives better protection from sprinkles and airborne infections as compared to the cloth mask [8].

- Dental surgeons, hygienists and other dental aides can keep wearing the cloth mask until they are in direct contact with the patients. As soon as they are called for assistance, they should wear N95 respirator mask and PPE kits [9].

- Before commencement of the procedure, dental surgeon should perform the hand hygiene exercises and should remain cautious not to touch their face covering thereafter [10].

\section{Use of PPE kits for clinical procedure}

Dental professionals should avail oneself with the PPE as per OSHA PPE norms. Dental surgeons should make sure to use PPE kits and make judicial decision regarding:

- When to use PPE

- What part of PPE is important
- How to appropriately wear, use and doff PPE

- How to appropriately discard or dispose the PPE [11].

Personal protective equipment (PPE)

A personal protective equipment should incorporate:

1. Surgical gown

2. Surgical gloves

3. Face mask

4. Protective shields.

Surgical gowns

- $\quad$ Clean disengagement outfit should be worn before entering into patient room.

- $\quad$ Conform outfit in the event that it gets smeared [14].

Surgical gloves

- Before going into the patient room or care region, put on clean, non-clean gloves.

- Change gloves in the event that they become torn or vigorously defiled.

\section{Mask or respirator}

N95 Mask or respirator insures protection from the harmful airborne infectious aerosols better than the cloth and surgical masks [2].

\section{Eye protection}

- $\quad$ Clinicians are advised to put on eye security before going into the patient room or care region.

- $\quad$ Personal eyeglasses are not considered as a full proof protective equipment. It should be clubbed with goggles or full coverage face shield [13].

- Operators are advised to wear a full-face shield.

Hand hygiene protocol

Hand hygiene is very important before and after evacuating PPE during the expulsion procedure. There are chances of transferring of microbes to exposed hands [15].

Use of alcohol-based sanitisers with 70 - 95\% alcohol or washing hands with disinfectant handwash for at least 20 seconds. In the event that hands are dirty, use soap and water before coming back to alcohol- based sanitisers [16]. 


\section{Screening of dental professionals}

Self-monitoring form for operators

- Name:

- Address:

- Detailed travel history:

- $\quad$ Travel from affected geographic areas*?

Dates:________ to __________

Arrival in Ghaziabad:

- $\quad$ Did/Does the operator have a fever? Yes No

If Yes

Highest measured temperature: $\square{ }^{\circ} \mathrm{F}{ }^{\circ} \mathrm{C}$

- Do you have symptoms of lower respiratory illness (LRI) (e.g. cough or shortness of breath)?

$\square$ Cough $\square$ Sore throat $\square$ Difficulty breathing

- History of hospitalization for severe LRI (e.g. pneumonia, ARDS)?

- In the last 14 days:

Do you Have any close contact with a lab-confirmed COVID-19 patient?

Dates of contact with COVID-19 lab-confirmed case:

________to_______

Nature of contact: $\square$ Family/Household $\square$ Coworkers.

\begin{tabular}{|l|c|l|l|}
\hline S. No. & Symptom & Yes & No \\
\hline & Temp & & \\
\hline & Subjective Fever & & \\
\hline & Cough & & \\
\hline & Sore Throat & & \\
\hline & Shortness of Breath & & \\
\hline & Chnny Nose & & \\
\hline & Muscle Aches & & \\
\hline & Headache & & \\
\hline & Fatigue & & \\
\hline & Abdominal Pain & & \\
\hline & Nausea or Vomiting & & \\
\hline & Diarrhea & & \\
\hline
\end{tabular}

\section{Possible exposure counsel}

In any event, when dental health care professionals screen patients for respiratory diseases, they may treat a dental crisis persistent who is later affirmed to have COVID-19.
Dental health care professionals should organize an approach to contact all patients who got crisis dental consideration in the dental setting 48 hours subsequent to getting crisis care. Dental health care professionals ought to inquire as to whether they are displaying any signs or manifestations of COVID-19. On the off chance that a patient reports signs or side effects of COVID-19, allude the patient to their clinical supplier for appraisal and follow CDC's Healthcare Personnel with Potential Exposure Guidance [17].

\section{Possibility and crisis planning}

Due to less production, many vendors have expressed their fear regarding less availability of PPE kits. CDC has advised increased production and availability of advance supplies of PPE.

If there is a need for PPE stock limitation, the DHCP who might be at higher risk for COVID-19, for example, those with any systemic diseases, those falling under higher age group, pregnant females from performing dental procedures [18].

- $\quad$ DHCP implies to everyone serving in dental communal settings who are at the high risk for immediate exposure to the patients, consisting of:

- $\quad$ Body waste and secretions

- Infected clinical supplies

- Infected natural surfaces

- $\quad$ Infected air

- $\quad$ Fever might be inner or declared.

- A respirator or mask is worn on the face, covers the nose and mouth, and is used to protect the wearer's danger of breathing in dangerous airborne particles, gases, or fumes. Respirators are accredited by the CDC/NIOSH, including those proposed for use in medical field [19].

Usage of masks should facilitate a total respiratory security as per OSHA Respiratory Protection standard (29 CFR 1910.134external symbol).

\section{Conclusion}

The corona virus (COVID-19) has emerged as a challenge for health care professionals. Routine general dental procedures have been put to a halt in countries influenced by COVID-19 disease and the facilities are taking place under strict protective protocols. As per WHO and ECDC guideline, this article is primarily aiming at precautions and preventions measures to be taken by dental health care professionals. 


\section{Bibliography}

1. Woo PC., et al. "Coronavirus genomics and bioinformatics analysis". Viruses 2 (2010): 1804-1820.

2. Centers for Disease Control and Prevention (CDC). "Update: Outbreak of severe acute respiratory syndrome-worldwide 2003". Morbidity and Mortality Weekly Report 52.12 (2003): 241-246.

3. Yin Y and Wunderink RG. "MERS, SARS and other coronaviruses as causes of pneumonia”. Respirology 23 (2018): 130-137.

4. World Health Organization. WHO Statement Regarding Cluster of Pneumonia Cases in Wuhan, China Geneva (2020).

5. Zaki AM., et al. "Isolation of a novel coronavirus from a man with pneumonia in Saudi Arabia". The New England Journal of Medicine 367 (2012): 1814-1820.

6. Tyrrell DAJ and Myint SH. "Chapter 60: Coronaviruses". In Barson $1 \mathrm{~S}$, editor. Medical microbiology. $4^{\text {th }}$ edition. Galveston: University of Texas Medical Branch at Galveston (1996).

7. Woo PC., et al. "Coronavirus diversity, phylogeny and interspecies jumping". Bulletin of Experimental Biology and Medicine 234 (2009): 1117-1127.

8. European Centre for Disease Prevention and Control data. Geographical distribution of 2019-nCov cases (2020).

9. World Health Organization, 2019-n CoV Situation Report-22 (2020).

10. Gralinski L and Menachery V. "Return of the Coronavirus: 2019- nCoV". Viruses 12 (2020): 135.

11. Chen Z., et al. "From SARS-CoV to Wuhan 2019- nCoV Outbreak: Similarity of Early Epidemic and Prediction of Future Trends". Cell Press (2020).

12. Buchholz U., et al. "Contact investigation of a case of human novel coronavirus infection treated in a German hospital, October-November 2012". Eurosurveillance 18 (2013): 20406.
15. Lambeir AM., et al. "Dipeptidylpeptidase IV from bench to bedside: An update on structural properties, functions, and clinical aspects of the enzyme DPP IV". Critical Reviews in Clinical Laboratory Sciences 40 (2003): 209-294.

16. Chu H., et al. "Productive replication of Middle East respiratory syndrome coronavirus in monocyte-derived dendritic cells modulates innate immune response". Virology 454-455 (2014): 197-205.

17. Zhou J., et al. "Active replication of Middle East respiratory syndrome coronavirus and aberrant induction of inflammatory cytokines and chemokines in human macrophages: Implications for pathogenesis". The Journal of Infectious Diseases 209 (2014): 1331-1342.

18. Hamre D and Procknow JJ. "A new virus isolated from the human respiratory tract". Proceedings of the Society for Experimental Biology and Medicine 121 (1966): 190-193.

19. Hui DS., et al. "The continuing 2019-nCoV epidemic threat of novel coronaviruses to global health -The latest 2019 novel coronavirus outbreak in Wuhan, China". The International Journal of Infectious Diseases (2020): 264-266.

20. Holshue ML., et al. "First Case of 2019 Novel Coronavirus in the United States". The New England Journal of Medicine (2020).

\section{Assets from publication with us}

- Prompt Acknowledgement after receiving the article

- Thorough Double blinded peer review

- Rapid Publication

- Issue of Publication Certificate

- High visibility of your Published work

Website: www.actascientific.com/

Submit Article: www.actascientific.com/submission.php

Email us: editor@actascientific.com

Contact us: +919182824667

13. Coronavirinae in Viral Zone (2019).

14. Subissi L., et al. "One severe acute respiratory syndrome coronavirus protein complex integrates processive RNA polymerase and exonuclease activities". Proceedings of the $\mathrm{Na}$ tional Academy of Sciences of the United States of America 111 (2014): E3900-E3909. 